\title{
Impact on parents of bronchiolitis hospitalization of full-term, preterm and congenital heart disease infants
}

\author{
Alexandre Lapillonne ${ }^{1,2}$, Antoine Regnault ${ }^{3,4^{*}}$, Véronique Gournay ${ }^{5}$, Jean-Bernard Gouyon ${ }^{6}$, Hélène Gilet ${ }^{3}$, \\ Daniela Anghelescu', Tatiana Miloradovich7, Benoit Arnould ${ }^{3}$ and Guy Moriette ${ }^{8,9}$
}

\begin{abstract}
Background: The objective of this work was to explore the impact on parents of the bronchiolitis hospitalization of

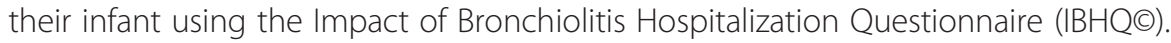

Methods: Four hundred sixty-three infants aged less than 1 year and hospitalized for bronchiolitis were included in a French observational study during the 2008-2009 season. Parents were asked to complete the IBHQ at hospital discharge and 3 months later. IBHQ scores, ranging from 0 (no impact) to 100 (highest impact), were compared according to gestational age (full-term, 33-36 wGA, $\leq 32$ wGA) and the presence of congenital heart disease (CHD). The potential drivers of impact were explored using multivariate linear regressions.

Results: The study included 332 full-terms, 71 infants born at 33-36 wGA, and 60 at $\leq 32$ wGA; 28 infants had a CHD. At hospital discharge, 9 of the $12 \mathrm{IBHQ}$ mean scores were above 40, indicating a marked impact on parents. Three months later, all mean scores were lower but 5 were still greater than 40 . At discharge, the length of hospitalization had a significant effect on IBHQ worries and distress, fear for future, guilt and impact on daily organization scores ( $p<0.01)$; the parents' educational level had a significant effect on IBHQ worries and distress, fear for future, impact on daily organization and financial impact scores $(p<0.05)$. The only statistically significant difference found between the parents of preterm and full-term infants was for the physical impact score at discharge $(p=0.004)$.

Conclusions: Bronchiolitis hospitalization has conspicuous emotional, physical and organizational consequences on parents and siblings, which persist 3 months after hospital discharge. The main drivers of the impact were length of hospital stay and parents' educational level, while infants' gestational age or the presence of a CHD had little influence.
\end{abstract}

Keywords: Bronchiolitis, Family, Infant care, Hospitalization

\section{Background}

Bronchiolitis is a viral obstructive bronchial disease occurring in epidemics in infants aged 1-24 months, and manifesting as dyspnoea with tachypnoea, restricted expiration, chest hyperinflation and respiratory distress potentially interfering with feeding; auscultation is dominated by crepitant or subcrepitant rales, rapidly

\footnotetext{
* Correspondence: aregnault@mapigroup.com

${ }^{3}$ MAPI Consultancy, Lyon 69003, France

${ }^{4}$ EA4275 SPHERE Biostatistique, Pharmacoépidémiologie et Mesures

Subjectives en Santé, Université de Nantes, Nantes 44035, France

Full list of author information is available at the end of the article
}

followed by sibilant rales and wheezing [1]. Bronchiolitis is most often caused by respiratory syncytial virus (RSV) [2]. It usually affects infants less than 2 years old, with a peak age of 3-6 months; it is the main cause of hospitalization during the first year of life, therefore exposing many families to the risk of having their infant admitted to hospital [3].

Being hospitalized is difficult for infants but it is also a stressful event for parents $[4,5]$. The impact on parents of their infant's hospitalization has been widely studied in the context of pediatric intensive care units (PICU) [6-10]; this research confirmed the distressing impact

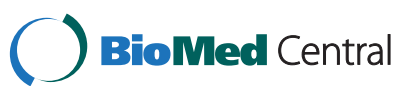


that this experience can have on parents and siblings. Hence examining the impact on parents of the hospitalization of their infant for a cause as frequent as bronchiolitis is of particular relevance.

Prematurity and congenital heart diseases (CHD) are major risk factors of bronchiolitis hospitalization [3,1113]. The hospital admission of these infants at-risk may have a specific impact on parents, which is worth investigating. Furthermore, in the context of a hospitalization for bronchiolitis, many factors are likely to affect parents' experience (e.g. demographics, child's medical history, or in-ward care). Hence, exploring the drivers of this impact would enable a better understanding of its various levers.

Even though several self-administered questionnaires evaluate the impact of an infant's illness on the family, none of them specifically measures the distress of parents whose children are hospitalized for bronchiolitis. The Impact of Bronchiolitis Hospitalization Questionnaire $\left(\mathrm{IBHQ}{ }^{\odot}\right)$ was thus developed to specifically evaluate the impact on parents of the hospitalization of their child for bronchiolitis. The questionnaire was then validated in an observational study in infants aged less than 1 year and hospitalized for bronchiolitis only.

Based on this validation study, the objective of this work was to explore the various facets (emotional, physical, organizational, financial, etc.) of the impact on parents of the hospitalization of their infant for bronchiolitis. We also aimed to specifically evaluate the impact in different populations at-risk (preterm infants and infants with CHD) and to further assess the potential drivers of this impact.

\section{Methods}

\section{Study design}

A multicenter, longitudinal, prospective, observational study was conducted in France from October 2008 to July 2009. Its primary objective was to finalize and validate the $\mathrm{IBHQ}^{\odot}$; exploring the impact on parents of the bronchiolitis hospitalization of their infant was a secondary objective of the study. Eighty-six attending physicians experienced in the management of infants hospitalized for bronchiolitis (49 pediatricians, 21 neonatologists, 3 pediatric cardiologists and 13 pediatric pneumologists) from 77 hospitals (including 13 academic centres) all over the French territory, were involved in this study. Each physician was asked to recruit 7 infants each, with the following distribution: 3 preterm infants (birth at $<37$ weeks of gestational age, wGA); 3 fullterms; and 1 infant with CHD. This distribution was meant to ensure that the study sample would include enough infants from these three key populations; however, because of recruitment difficulties, this constraint was released during the course of the study (about half of children were recruited after the removal of distribution recruitment requirement).

Inclusion criteria were: infants less than 1 year of age, hospitalized for bronchiolitis only, and not participating in another clinical study; parents able to read, understand and complete a questionnaire in French. The infants were recruited at the study visit preceding hospital discharge.

Investigators completed a case report form including data on the bronchiolitis hospitalization - severity, duration, in-ward management - and the infant's medical history - health care received during the neonatal period and risk factors for bronchiolitis (including CHD, chronic lung disease, and family history of allergy). The study population of infants was divided into three gestational age groups to be further analyzed: full-terms (born at $\geq 37$ wGA); $33-36$ wGA preterm infants, and very preterm infants (born at $\leq 32 \mathrm{wGA}$ ).

Parents were asked to fill-in a questionnaire in the week following hospital discharge and three months later, with no specific requirement regarding which parent should complete the questionnaire. The discharge questionnaire was given to parents by physicians at the end of the inclusion visit, and comprised the IBHQ as well as demographics and hospitalization-related socioeconomic questions; the 3-months follow-up questionnaire was sent to parents by mail and included the IBHQ, and socio-economic questions referring to the follow-up of the hospitalization.

\section{The Impact of Bronchiolitis Hospitalization Questionnaire $\left(\mathrm{IBHQ}{ }^{\circ}\right)$}

The IBHQ is a self-administered questionnaire specifically developed to comprehensively assess the impact on parents of their infant hospitalization for bronchiolitis $[14,15]$. The development process followed a rigorous methodology including systematic literature review and several steps of interviews with both clinicians and parents whose infants have been recently hospitalized for bronchiolitis. Two versions were developed: one to be completed soon after hospital discharge (DC), and the second to be completed 3 months later to assess the impact during the follow-up (FU) period. These two versions included similar items that assessed the same dimensions but slightly differed in their wording.

Each IBHQ version comprises thirty core items. All these items were to be completed by all the parents, and allowed the calculation of seven core dimension scores: worries and distress, fear for future, guilt, impact on daily organization, physical impact, impact on behavior with hospitalized infant, and financial impact. In addition to the core items, each IBHQ version comprises sixteen optional items. These items, which only addressed specific situations, were to be completed only 
by the concerned parents, and allowed the calculation of five additional dimension scores: disturbed breastfeeding, physical reaction of the hospitalized infant, impact on feeding of hospitalized infant, impact on behavior with other children, and siblings' reaction. The IBHQ$\mathrm{DC}$ and IBHQ-FU were previously proved to be reliable and valid.

All dimension scores range from 0 (no impact) to 100 (highest possible impact of the bronchiolitis hospitalization). A score of 0 corresponds to the normal situation; conversely, any score greater than 0 indicates that the hospitalization had an impact on the corresponding dimension. However, no interpretation rule enables a formal definition of a meaningful impact.

\section{Statistical analyses}

\section{1) General considerations}

The description of socio-demographic and clinical characteristics was performed for all the eligible infants. The analyses of the impact of bronchiolitis hospitalization were performed on all parents of eligible infants who completed both the IBHQ-DC and the IBHQ-FU questionnaires.

All analyses were performed using SAS statistical software version 9.2 (SAS Institute, Cary, NC, USA).

3) Assessment of the impact of bronchiolitis hospitalization on parents

IBHQ-DC and IBHQ-FU scores were compared according to the gestational age group (full-terms, 33-36 wGA, and $\leq 32 \mathrm{wGA}$ ) and to the presence of $\mathrm{CHD}$ risk factor using univariate analysis of variance (ANOVA).

Multivariate linear regression models with stepwise selection were used to identify factors having an independent statistically significant effect on the impact of bronchiolitis hospitalization on parents. The factors whose effect on impact scores were tested pertained to different areas: infant's characteristics (age at hospitalization, gender, number of siblings), birth conditions (infant from multiple pregnancy, premature birth, associated CHD, Apgar score, hospitalization in neonatology units, supplemental oxygen required for $>24 \mathrm{~h}$, mechanical and/or non-invasive ventilation, supplemental oxygen-dependency at 28 days and at $36 \mathrm{wGA})$, parent's characteristics (age, gender, education level, professional status), and characteristics of the bronchiolitis hospitalization (duration of hospitalization, department of hospitalization, infusion or parenteral nutrition, enteral nutrition, oxygen therapy, assisted ventilation, non-invasive ventilation, respiratory physiotherapy) as well as of the end of hospitalization and follow-up period (residual respiratory signs at discharge, weight loss, digestive problems, respiratory physiotherapy, oxygen prescription, corticosteroids or bronchodilator prescription). The strength of the link between each variable retained in the multivariate regression after the stepwise selection and the impact of bronchiolitis hospitalization on parents was evaluated using parameter estimates: for continuous variables, the parameter estimate corresponds to the change in the score for a change of 1 unity of the explanatory variable, all other things being equal; for categorical variables, it corresponds to the difference in score for the associate category compared to the reference category, all other things being equal.

\section{Ethics}

The study was conducted in accordance with the principles established in the Declaration of Helsinki and in compliance with local regulatory requirements. The appropriate national authorities and institutional review boards approved the protocol before study commencement. Only parents that returned the signed informed consent form took part in the study.

\section{Results}

\section{Description of the population}

Four hundred and seventy infants hospitalized for bronchiolitis only were included in the study; of these, 7 did not meet one of the inclusion criteria and were not included in the analyses. The parents of eligible infants completed 368 IBHQ-DC and 339 IBHQ-FU; 315 parents completed both IBHQ-DC and IBHQ-FU.

Of the 463 eligible infants, $75 \%$ were less than 5 months old and $72 \%$ had at least one sibling (Table 1 ). The study included 28 (6\%) CHD infants, of which 2 (7\%) born at $33-36$ wGA and $3(11 \%)$ at $\leq 32$ wGA. Among the 435 infants without CHD, 69 (16\%) were born at 33-36 wGA and 57 (13\%) at $\leq 32$ wGA. One hundred and forty seven infants (32\%) had been hospitalized in neonatology units at birth, with a mean duration of stay of 12 days for full-term infants $(\mathrm{N}=33)$ and 41 days for preterm infants $(\mathrm{N}=114)$ (Table 2). The mean duration of bronchiolitis hospitalization was 6.6 days, with $74 \%$ of infants hospitalized in general pediatrics only, $14 \%$ in PICUs, and $7 \%$ in neonatology units without intensive care facilities (Table 1). Most of the parents who completed the questionnaire were mothers; only 26 fathers (5.6\%) completed the discharge questionnaire, 21 discharge questionnaires (4.5\%) were completed by both parents, and the information on which parent completed the IBHQ was missing for the other questionnaires. Fathers were slightly older (mean of 33.6 years and 30.1 years for mothers) and more often full-time employed than mothers $(65.4 \%$ and $33.1 \%$ for mothers), while mothers were more often homemakers (42.5\%). 
Table 1 Characteristics and birth conditions of the infants included in the study and characteristics of bronchiolitis hospitalization

\begin{tabular}{|c|c|c|}
\hline & & Eligible infants $(\mathrm{N}=463)$ \\
\hline \multirow[t]{3}{*}{ Age at hospitalization (months) } & Mean (SD) & $3.3(2.7)$ \\
\hline & Median (Q1 - Q3) & $2.5(1.3-5.0)$ \\
\hline & Min - Max & $0.3-12.0$ \\
\hline Sex - n (\%) & Male & $254(54.9)$ \\
\hline \multirow[t]{2}{*}{ Siblings - n (\%) } & 0 & $120(25.9)$ \\
\hline & 1 or more & $335(72.4)$ \\
\hline Multiple pregnancies - n (\%) & & $36(7.8)$ \\
\hline \multirow[t]{8}{*}{ Gestational age $-\mathrm{n}(\%)$} & Infant with $\mathrm{CHD}(\mathrm{N}=28)-\mathrm{n}(\%)$ & \\
\hline & Full-term & $23(82.1)$ \\
\hline & 33-36 wGA & $2(7.1)$ \\
\hline & $\leq 32 w G A$ & $3(10.7)$ \\
\hline & Infant without CHD (N=435) - n (\%) & \\
\hline & Full-term & $309(71.0)$ \\
\hline & $33-36$ wGA & $69(15.9)$ \\
\hline & $\leq 32 w G A$ & $57(13.1)$ \\
\hline \multicolumn{2}{|l|}{ Chronic lung disease - n (\%) } & $31(6.7)$ \\
\hline \multicolumn{2}{|l|}{ Family's allergy history - n (\%) } & $120(25.9)$ \\
\hline \multicolumn{2}{|l|}{ Hospitalization in neonatal unit - n (\%) } & $147(31.8)$ \\
\hline \multirow[t]{3}{*}{ Duration of hospitalization (days) } & Mean (SD) & $6.6(4.6)$ \\
\hline & Median (Q1 - Q3) & $5.0(4.0-8.0)$ \\
\hline & Min - Max & $1.0-46.0$ \\
\hline \multirow[t]{4}{*}{ Hospitalization department (\%) } & General pediatrics (only) & 73.9 \\
\hline & Intensive care department & 14.3 \\
\hline & Neonatal unit (but not intensive care) & 7.1 \\
\hline & Other department & 4.8 \\
\hline \multirow[t]{2}{*}{ RSV test (\%) } & & 91.8 \\
\hline & RSV-positive & 72.0 \\
\hline \multirow[t]{4}{*}{ Medications used (N=330) $(\%)$} & Bronchodilators & 57.3 \\
\hline & Antibiotics & 57.3 \\
\hline & Corticosteroids & 31.5 \\
\hline & Anti-reflux treatment & 20.0 \\
\hline \multirow[t]{6}{*}{ Non-medicated treatments $(\mathrm{N}=455)(\%)$} & Respiratory physiotherapy & 95.6 \\
\hline & Infusion or parenteral nutrition & 37.6 \\
\hline & Oxygen therapy & 64.6 \\
\hline & Enteral nutrition & 29.9 \\
\hline & Non-invasive ventilation & 13.0 \\
\hline & Assisted ventilation & 4.8 \\
\hline
\end{tabular}

a Several medicated or non-medicated treatments could be reported.

Impact of bronchiolitis hospitalization on parents at hospital discharge and three months later

IBHQ scores at hospital discharge ranged between 66.6 (worries and distress) and 21.4 (financial impact); nine of the twelve mean scores were above 40 (Table 3). At follow-up, the mean scores ranged between 59.0 (fear for future) and 13.3 (financial impact). All mean scores were lower three months after hospital discharge, with 5 of them being still greater than 40 .

\section{Impact of bronchiolitis hospitalization on parents according to gestational age}

The IBHQ scores at discharge and follow-up in the three gestational age groups are presented in Figure 1. At discharge, the physical impact score was significantly lower 
Table 2 Characteristics of the hospitalization in neonatal unit at birth

\begin{tabular}{|c|c|c|}
\hline & \multicolumn{2}{|c|}{$\begin{array}{l}\text { Eligible infants hospitalized in } \\
\text { neonatal unit at birth }(\mathrm{N}=147)\end{array}$} \\
\hline & Full-term $(\mathrm{N}=33)$ & Preterm $(\mathrm{N}=114)$ \\
\hline \multicolumn{3}{|l|}{ Duration of hospitalization (days) } \\
\hline Mean (SD) & $12.1(17.4)$ & $40.6(37.7)$ \\
\hline Median (Q1 - Q3) & $7.0(4.0-16.0)$ & $28.0(12.0-60.0)$ \\
\hline Min - Max & $1.0-90.0$ & $7.0-222.0$ \\
\hline Supplemental oxygen >24h (\%) & 39.4 & 55.3 \\
\hline Mechanical ventilation (\%) & 24.2 & 47.4 \\
\hline Non-invasive ventilation (\%) & 18.2 & 55.3 \\
\hline $\begin{array}{l}\text { Supplemental oxygen } \\
\text { requirement at } 28 \text { days (\%) }\end{array}$ & 3.0 & 20.2 \\
\hline $\begin{array}{l}\text { Supplemental oxygen } \\
\text { requirement at } 36 \text { wGA (\%) }\end{array}$ & 3.0 & 13.2 \\
\hline
\end{tabular}

in parents of $\leq 32 \mathrm{wGA}$ infants as compared to parents of more mature infants: mean scores were of 47 for parents of $\leq 32$ wGA infants, 54 for parents of 33-36 wGA infants and 57 for full-terms' parents $(p=0.004)$; other core scores did not significantly differ between parents of full-term and premature infants. No statistically significant difference was observed in mean optional scores between the three groups.

At follow-up, no statistically significant differences were noticed between the mean scores of parents of fullterm, 33-36 wGA and $\leq 32$ wGA infants, for either core or optional scores.

\section{Impact of bronchiolitis hospitalization on parents} according to CHD risk factor

At discharge and follow-up, parents of CHD infants reported lower mean scores, indicating a lower impact as compared to parents of infants without CHD (Figure 2); none of these differences was statistically significant.

\section{Multivariate model of the impact on parents of bronchiolitis hospitalization}

The results of the multivariate models performed on IBHQ scores at discharge are presented in the Tables 4 and 5 , for the core and optional scores respectively.

None of the studied factors systematically had a significant impact on all IBHQ scores. Two factors had a statistically significant effect on at least 4 scores: the length of hospital stay and the parents' educational level. Longer hospitalization was associated with higher scores for worries and distress, fear for future, impact on daily organization, financial impact, and impact on feeding of hospitalized infant. Parents' educational level had a significant effect on worries and distress, fear for future, guilt, and impact on daily organization scores, with a non linear pattern of association: parents in extreme categories $(<5$ and $>16$ years of education) seemed to experience less emotional impact and higher daily organization impact than parents having 6-15 years of education. Moreover, each IBHQ score was specifically affected by other factors.

As for simple comparisons, the gestational age group was only significantly associated with the physical impact IBHQ scores in the multivariate models.

Results of the multivariate regression analyses at follow-up showed a similar pattern (Additional file 1: Table S1 and Additional file 2: Table S2): only the length of hospitalization duration and the parents' educational level had a statistically significant impact on at least 4 scores; different other factors specifically affected various IBHQ-FU scores.

Table 3 Description of IBHQ scores at hospital discharge and at the three month follow-up

\begin{tabular}{|c|c|c|c|c|c|}
\hline & \multirow[t]{2}{*}{ IBHQ score } & \multicolumn{2}{|c|}{ Discharge } & \multicolumn{2}{|c|}{ Follow-up } \\
\hline & & $\mathbf{N}$ & Mean (SD) & $\mathbf{N}$ & Mean (SD) \\
\hline \multirow[t]{7}{*}{ Core scores } & Worries and distress & 315 & $57.5(23.5)$ & 314 & $45.4(26.8)$ \\
\hline & Fear for future & 306 & $66.6(27.2)$ & 308 & $59.0(28.3)$ \\
\hline & Guilt & 313 & $38.0(25.5)$ & 314 & $34.1(26.6)$ \\
\hline & Impact on daily organization & 314 & $62.7(23.6)$ & 310 & $18.4(18.8)$ \\
\hline & Physical impact & 311 & $55.4(21.0)$ & 306 & $39.6(24.2)$ \\
\hline & Impact on behavior with hospitalized infant & 311 & $55.3(25.5)$ & 310 & $45.8(24.4)$ \\
\hline & Financial impact & 310 & $21.4(19.4)$ & 315 & $13.3(14.0)$ \\
\hline \multirow[t]{5}{*}{ Optional scores } & Disturbed breastfeeding & 91 & $49.5(33.0)$ & 82 & $43.5(35.2)$ \\
\hline & Physical reaction of hospitalized infant & 298 & $30.5(25.9)$ & 302 & $18.0(22.0)$ \\
\hline & Impact on feeding of hospitalized infant & 306 & $40.1(26.1)$ & 311 & $15.6(18.9)$ \\
\hline & Impact on behavior with other children & 241 & $56.6(27.5)$ & 234 & $39.8(28.7)$ \\
\hline & Siblings' reaction & 213 & $63.1(25.5)$ & 212 & $57.9(24.8)$ \\
\hline
\end{tabular}

All IBHQ scores range between 0 (no impact) and 100 (highest impact). 


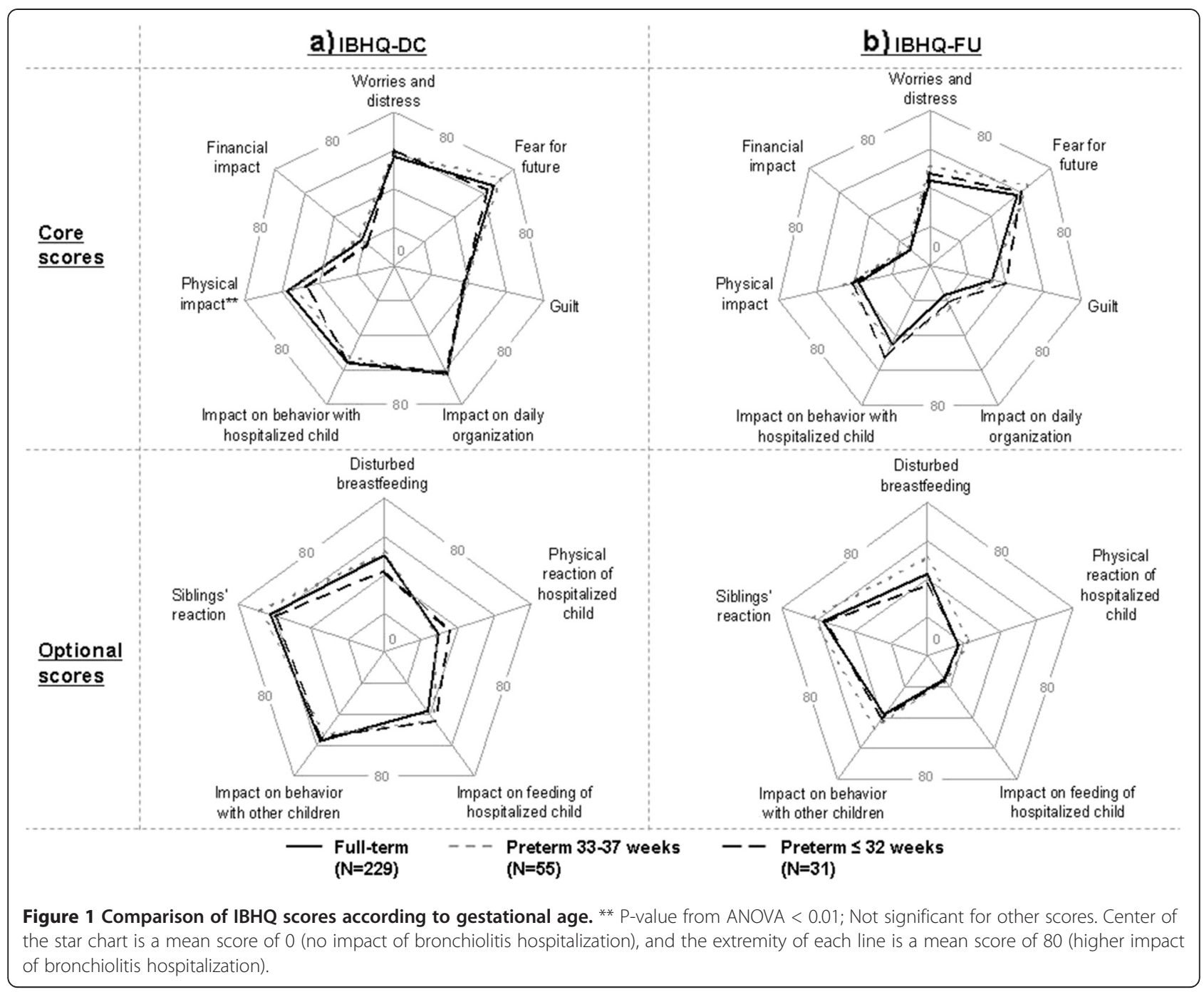

\section{Discussion}

This study showed that the hospitalization of an infant for bronchiolitis has a multidimensional impact on its parents as well as on the whole family: emotional and physical impact, impact on daily life organization and parenting role, and impact on siblings. Among the various studied aspects, only the financial impact and to a lesser extent parent's perception on the physical reaction of the hospitalized infant revealed lower levels of impact. Unsurprisingly, the impact at hospital discharge was consistently stronger than the impact 3 months later; however, the impact 3 months after hospital discharge remained notable for many aspects (especially for emotional consequences, parenting roles, and reactions of siblings).

One of the main challenges of this study was to interpret the IBHQ results, as this is the first study using the IBHQ, and no control group can be defined to compare the specific impact of hospitalization for bronchiolitis with the impact of hospitalization for other reasons since the IBHQ is a specific questionnaire that is not suitable for other populations / pathologies than parents of children hospitalized for bronchiolitis. Given the absence of clear rules for the interpretation of scores, it had to rely largely on the content of the questions. For example, to obtain a value of 40 for the mean guilt score at hospital discharge, parents would have answered "very much" or "extremely" to at least one of the three questions of the dimension (i.e. feeling guilty for leaving the infant in hospital, feeling guilty because of the infant's bronchiolitis, and feeling lonely). In light of this kind of considerations, it clearly appeared that the observed mean scores, which ranged between 40 and 60 for almost all scores, are indicative of a non-trivial impact.

The impact on parents of the hospitalization of their child was often investigated in the context of severe diseases, in a PICU context $[6-10,16]$. A literature review revealed the great emotional and physical impact on the parents of hospitalized critically ill children [17]; moreover, these hospitalizations were shown to have 


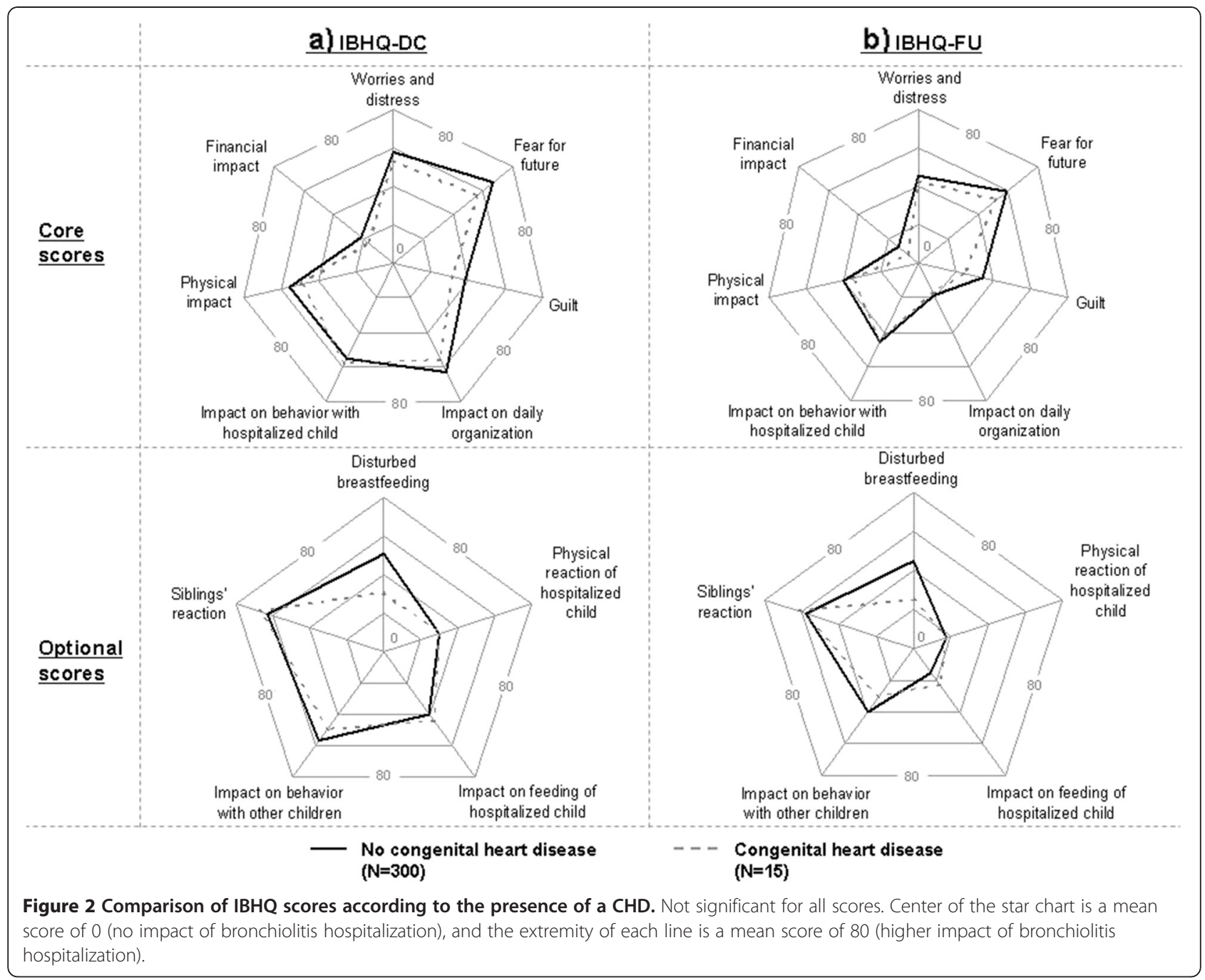

important consequences on the whole family. To our knowledge, a single previous study specifically explored the impact on parents of their infant's hospitalization for bronchiolitis in a small sample $(\mathrm{N}=46)$ of infants hospitalized with RSV-bronchiolitis [18]; this work showed a clear impact on emotional aspects and parenting role that persisted several weeks after hospital discharge. The present study confirmed these key findings in a much larger sample, since most of the results were based on more than 300 infants. Moreover, our results provide a broader spectrum of this impact, by adding physical and daily life organization consequences to the picture as well as by outlining the distressful impact on the siblings of the hospitalized infant.

We also analyzed the impact in different subgroups of parents of infants at high-risk of hospitalization for bronchiolitis, i.e. preterm and CHD infants. The few differences found depending on gestational age were small and did not appear meaningful. As for parents of infants with CHD, unexpectedly, they seemed overall less affected by the bronchiolitis hospitalization. This could indicate a different perception of the bronchiolitis hospitalization in these parents whose infants had already experienced more serious hospitalizations; their reaction to the bronchiolitis hospitalization may be mitigated by their previous difficult experiences, and they may have already created strategies to cope with the burden of their infant's hospitalization. Nevertheless, these findings should be interpreted with caution given the small observed impact differences as well as the limited number of CHD infants included in the analyses.

We also evaluated the main drivers of the impact of bronchiolitis hospitalizations on parents: none of the factors considered in these analyses consistently affected all the dimensions of the impact. Nonetheless two factors were associated to a higher impact on several aspects: duration of hospitalization and parents' educational level. Hospital length of stay can be considered as a surrogate marker of the severity of the hospitalization, which has already been shown as a key driver of impact 
Table 4 Multivariate regression models of IBHQ core scores at discharge

\begin{tabular}{|c|c|c|c|c|c|c|c|c|}
\hline & & \multicolumn{7}{|c|}{ IBHQ core score - Discharge } \\
\hline & & $\begin{array}{l}\text { Worries } \\
\text { and } \\
\text { distress }\end{array}$ & $\begin{array}{l}\text { Fear for } \\
\text { future }\end{array}$ & Guilt & $\begin{array}{l}\text { Impact on daily } \\
\text { organization }\end{array}$ & $\begin{array}{l}\text { Physical } \\
\text { impact }\end{array}$ & $\begin{array}{l}\text { Impact on behavior } \\
\text { with hospitalized } \\
\text { infant }\end{array}$ & $\begin{array}{l}\text { Financial } \\
\text { impact }\end{array}$ \\
\hline & & $\begin{array}{l}\left(R^{2}=\right. \\
0.137)\end{array}$ & $\begin{array}{l}\left(R^{2}=\right. \\
0.122) \\
\end{array}$ & $\begin{array}{l}\left(R^{2}=\right. \\
0.094) \\
\end{array}$ & $\left(R^{2}=0.122\right)$ & $\begin{array}{l}\left(R^{2}=\right. \\
0.056)\end{array}$ & $\left(R^{2}=0.014\right)$ & $\begin{array}{l}\left(R^{2}=\right. \\
0.182)\end{array}$ \\
\hline Intercept & & 59.8 & 77.1 & 42.6 & 38.3 & 48.4 & 44.4 & -1.1 \\
\hline \multirow{5}{*}{$\begin{array}{l}\text { Level of education of parent (years) } \\
\text { Ref: Other }\end{array}$} & $\leq 5$ & -24.7 & -11.8 & -33.3 & 24.6 & & & \\
\hline & $6-9$ & -2.9 & -5.4 & -28.0 & -15.9 & & & \\
\hline & $10-12$ & -5.8 & -8.4 & -9.0 & -4.0 & & & \\
\hline & $13-15$ & -15.5 & -16.2 & -19.8 & 4.2 & & & \\
\hline & $\geq 16$ & -18.4 & -22.3 & -22.2 & 10.3 & & & \\
\hline P-value & & $<0.001$ & 0.004 & $\begin{array}{l}< \\
0.001\end{array}$ & $<0.001$ & & & \\
\hline \multicolumn{2}{|l|}{ Duration of hospitalization (days) } & 1.5 & 1.2 & & 0.9 & & & 0.9 \\
\hline \multicolumn{2}{|l|}{$P$-value } & $<0.001$ & 0.006 & & 0.015 & & & 0.007 \\
\hline \multicolumn{2}{|l|}{$\begin{array}{l}\text { Infusion or parenteral nutrition during } \\
\text { hospitalization }\end{array}$} & & 6.7 & & & & & \\
\hline \multicolumn{2}{|l|}{$P$-value } & & 0.048 & & & & & \\
\hline \multicolumn{2}{|c|}{$\begin{array}{l}\text { Requirement of supplemental oxygen at } 28 \\
\text { days }\end{array}$} & & & -12.9 & & & & -19.0 \\
\hline \multicolumn{2}{|c|}{ P-value } & & & 0.041 & & & & 0.001 \\
\hline \multicolumn{2}{|l|}{$\begin{array}{l}\text { Non-invasive ventilation during } \\
\text { hospitalization }\end{array}$} & & & & -12.7 & & & \\
\hline \multicolumn{2}{|l|}{$P$-value } & & & & 0.009 & & & \\
\hline \multicolumn{2}{|c|}{$\begin{array}{l}\text { Corticosteroids or bronchodilator aerosols } \\
\text { planned after hospitalization }\end{array}$} & & & & -6.9 & & & \\
\hline \multicolumn{2}{|c|}{$P$-value } & & & & 0.027 & & & \\
\hline \multicolumn{2}{|l|}{ Sex of infant (male) } & & & & & -5.3 & & \\
\hline \multicolumn{2}{|l|}{ P-value } & & & & & 0.033 & & \\
\hline \multirow[t]{2}{*}{$\begin{array}{l}\text { Gestational age } \\
\text { Ref: } \leq 32 \text { WGA }\end{array}$} & $\begin{array}{l}33-37 \\
\text { WGA }\end{array}$ & & & & & 8.4 & & \\
\hline & $\begin{array}{l}\text { Full- } \\
\text { term }\end{array}$ & & & & & 12.0 & & \\
\hline \multicolumn{2}{|l|}{$P$-value } & & & & & 0.004 & & \\
\hline \multicolumn{2}{|l|}{ Infant from multiple pregnancy } & & & & & & 11.7 & \\
\hline \multicolumn{2}{|l|}{ P-value } & & & & & & 0.041 & \\
\hline \multicolumn{2}{|l|}{ Infant age at hospitalization (months) } & & & & & & & 0.5 \\
\hline \multicolumn{2}{|l|}{$P$-value } & & & & & & & $<0.001$ \\
\hline \multirow{2}{*}{$\begin{array}{l}\text { Respondent } \\
\text { Ref: both parents }\end{array}$} & Father & & & & & & & 15.9 \\
\hline & Mother & & & & & & & -9.9 \\
\hline \multicolumn{2}{|l|}{$P$-value } & & & & & & & $<0.001$ \\
\hline
\end{tabular}

on parents of the hospitalization of their infant in previous studies [4,5,7]. Parents' level of education equally had a significant effect on many aspects of the impact of hospitalization: worries and distress, fear for future, guilt, and impact on daily organization. However, no clear, consistent pattern was observed; the impact of bronchiolitis hospitalization is obviously dependent on the parents' level of education, but this relationship is not straightforward. Further research specifically focusing on this issue is warranted in order to get a better understanding of how hospitalizations for bronchiolitis affect parents with different educational levels.

Despite, the population of the present study seemed to be similar to the population of infants generally 
Table 5 Multivariate regression models of IBHQ optional scores at discharge

\begin{tabular}{|c|c|c|c|c|c|c|}
\hline & & \multicolumn{5}{|c|}{ IBHQ optional score - Discharge } \\
\hline & & $\begin{array}{l}\text { Disturbed } \\
\text { breastfeeding }\end{array}$ & $\begin{array}{l}\text { Physical reaction of } \\
\text { hospitalized infant }\end{array}$ & $\begin{array}{l}\text { Impact on feeding } \\
\text { of hospitalized } \\
\text { infant }\end{array}$ & $\begin{array}{l}\text { Impact on behavior } \\
\text { with other children }\end{array}$ & $\begin{array}{l}\text { Siblings' } \\
\text { reaction }\end{array}$ \\
\hline & & $\left(R^{2}=0.269\right)$ & $\left(R^{2}=0.078\right)$ & $\left(R^{2}=0.111\right)$ & $\left(R^{2}=0.126\right)$ & $\begin{array}{l}\left(R^{2}=\right. \\
0.090)\end{array}$ \\
\hline \multicolumn{2}{|l|}{ Intercept } & 43.9 & 7.8 & 44.0 & 64.3 & 53.0 \\
\hline \multicolumn{2}{|c|}{ Duration of hospitalization (days) } & & & 1.2 & & \\
\hline \multicolumn{2}{|l|}{$P$-value } & & & 0.007 & & \\
\hline \multirow[t]{3}{*}{$\begin{array}{l}\text { Hospitalization department } \\
\text { Ref: Other }\end{array}$} & $\begin{array}{l}\text { General pediatrics } \\
\text { (only) }\end{array}$ & & 19.6 & & & 3.2 \\
\hline & Intensive care & & 32.3 & & & 7.6 \\
\hline & $\begin{array}{l}\text { Neonatal unit (but } \\
\text { not intensive care) }\end{array}$ & & 28.0 & & & -13.1 \\
\hline \multicolumn{2}{|l|}{ P-value } & & 0.006 & & & 0.032 \\
\hline \multicolumn{2}{|c|}{$\begin{array}{l}\text { Infusion or parenteral nutrition during } \\
\text { hospitalization }\end{array}$} & 26.0 & & & & \\
\hline \multicolumn{2}{|c|}{$P$-value } & $<0.001$ & & & & \\
\hline \multicolumn{2}{|c|}{$\begin{array}{l}\text { Enteral nutrition during bronchiolitis } \\
\text { hospitalization }\end{array}$} & & & 11.5 & & \\
\hline \multicolumn{2}{|c|}{ P-value } & & & 0.002 & & \\
\hline \multicolumn{2}{|c|}{$\begin{array}{l}\text { Oxygen therapy during bronchiolitis } \\
\text { hospitalization }\end{array}$} & & 6.9 & & & \\
\hline \multicolumn{2}{|l|}{ P-value } & & 0.037 & & & \\
\hline \multicolumn{2}{|c|}{ Residual respiratory signs after hospitalization } & & & 8.8 & & \\
\hline \multicolumn{2}{|l|}{$P$-value } & & & 0.008 & & \\
\hline \multicolumn{2}{|c|}{$\begin{array}{l}\text { Corticosteroids or bronchodilator aerosols } \\
\text { planned after hospitalization }\end{array}$} & -26.8 & & & & \\
\hline \multicolumn{2}{|l|}{$P$-value } & 0.004 & & & & \\
\hline \multicolumn{2}{|c|}{ Infant age at hospitalization (months) } & & 0.3 & & -0.4 & \\
\hline \multicolumn{2}{|c|}{$P$-value } & & 0.019 & & 0.009 & \\
\hline \multicolumn{2}{|l|}{ No siblings } & & & & -38.5 & \\
\hline \multicolumn{2}{|l|}{$P$-value } & & & & $<0.001$ & \\
\hline \multicolumn{2}{|l|}{ Number of siblings } & & & & & 5.4 \\
\hline \multicolumn{2}{|l|}{$P$-value } & & & & & 0.003 \\
\hline
\end{tabular}

hospitalized for bronchiolitis, and the in-ward management was consistent with the current medical practice, the representativeness of the study sample could not be formally supported, in the absence of French reference data. The stratified enrolment procedure, which initially imposed the inclusion of preterm and CHD infants, increased the percentage of these cases in our study, and therefore our sample may be slightly different from the general population of infants hospitalized for bronchiolitis. The longer hospital stays observed in this study as compared to those retrieved from the 2005-2006 French National Hospitalizations Database (Programme de Médicalisation des Systèmes d'Information; PMSI) could be explained by these differences: the mean length of hospitalization in our study was of 6.6 days while the mean length of hospital stay for bronchiolitis in infants younger than one year was of 4.7 days in the PMSI database.

Some other specific features should also be taken into account when interpreting the results of the present study. The parent who completed the questionnaire was in most of the cases the mother (92\%). The parent's gender doubtlessly generates certain differences in the impact of the hospitalization [5] but the paucity of data collected from fathers in this study does not allow reliable conclusions on the impact on fathers of their infant's bronchiolitis hospitalization. Also, parents with low educational level might be underrepresented in this 
study sample because an inclusion criterion required the responding parent to be able to complete the questionnaire alone; this aspect could be particularly important since low educational level of the mother has been shown to be a risk factor for infant's hospitalization for bronchiolitis [19]. In addition, among the children whose parents accepted to participate in the study, those whose parents eventually completed the discharge questionnaire had less often CHD, had shorter hospitalizations, and less often admitted in intensive care units than children whose parents did not complete the discharge questionnaire, suggesting that they may have presented a less severe level of bronchiolitis. However, even for those parents, the bronchiolitis hospitalization of their children showed a clear impact, which demonstrates that, regardless of the severity of the disease, the hospitalization of the child is not of no consequence for the parents. Also, we could not take into account the potential impact on the follow-up assessment of additional family events that could have occurred in the three month period since discharge. Finally, this study was conducted in France and, even if most of the results are probably applicable to other Western European countries, certain cultural peculiarities might not be replicated in other cultures. In particular, the low financial impact of bronchiolitis hospitalization may be somewhat specific to France, where the costs of hospitalization are fully reimbursed by the social security system.

\section{Conclusions}

The hospitalization of an infant for bronchiolitis was confirmed to seriously impact its parents and family. This impact was shown to be multifaceted and persistent even three months after hospital discharge for several aspects, in particular the emotional dimensions of parents' impact, the parenting role, and the impact on siblings. The main drivers of this impact were length of hospital stay and parents' educational level; conversely, infants' gestational age and presence of a CHD had little influence on the impact on parents of their infant hospitalization for bronchiolitis.

\section{Additional files}

Additional file 1: Table S1. Multivariate regression models of $\mathrm{BH} \mathrm{BQ}$ core scores at follow-up.

Additional file 2: Table S2. Multivariate regression models of IBHQ optional scores at follow-up.

\section{Abbreviations}

CHD: congenital heart disease; IBHQ: Impact of Bronchiolitis Hospitalization Questionnaire; PICU: Pediatric Intensive Care Unit; RSV: Respiratory Syncytial Virus.

\section{Competing interests}

This study was sponsored by Abbott France. AL, JBG, VG and GM received honorarium for their scientific advice and expertise. AR, HG and BA are employees of Mapi Consultancy, consulting company commissioned by Abbott for this study. DA and TM are employees of Abbott.

\section{Authors' contributions}

AL, VG, JBG and GM provided clinical and scientific expertise on bronchiolitis's disease along the project, in particular for definition of objectives, patient inclusion and non-inclusion criteria validation, patien recruitment, interpretation of results, choice of concepts to be measured, and finalisation of the questionnaire, and critically reviewed the manuscript. AR participated in the validation study design, designed statistical analyses, participated in the interpretation of results, and drafted the manuscript. HG performed statistical analyses, participated in the interpretation of results and helped draft the manuscript. DA and TM participated in the interpretation of data and critically reviewed the manuscript. BA provided scientific expertise on the methodology used to develop the questionnaire and on the design of the study and of the statistical analysis, participated in the item generation of the questionnaire and in the interpretation of the study results, and critically reviewed the manuscript. All authors read and approved the final manuscript.

\section{Acknowledgments}

We want to thank all the physicians who participated in the study. We are also extremely grateful to the children and parents who have contributed to this study.

\section{Copyrights}

The Impact of Bronchiolitis Hospitalization Questionnaire $\left(\mathrm{IBHQ}^{\oplus}\right)$ is protected by copyright with all rights reserved to Abbott France. Do not use without permission. For information on, or permission to $\mathrm{use}_{\mathrm{IBHQ}}{ }^{\circ}$, please contact the Mapi Research Trust, 27 rue de la Villette 69003 Lyon, France. Tel: +33 (0) 472136575 - E-mail: trust@mapi.fr - website: www.mapi-trust. org.

\section{Author details}

${ }^{1}$ Université Paris Descartes, Paris 75006, France. ${ }^{2}$ APHP Necker Hospital, Paris 75015, France. ${ }^{3}$ MAPI Consultancy, Lyon 69003, France. ${ }^{4}$ EA4275 SPHERE Biostatistique, Pharmacoépidémiologie et Mesures Subjectives en Santé, Université de Nantes, Nantes 44035, France. ${ }^{5}$ Service de cardiologie pédiatrique, Centre Hospitalier Universitaire, Nantes 44093, France. ${ }^{6}$ Centre Hospitalier Universitaire de la Réunion, Groupe Hospitalier Sud Réunion, Centre d'Etudes Périnatales de I'Océan Indien, Saint-Pierre 97448, La Réunion. ${ }^{7}$ Medical Department, Abbott France, Rungis 94528, France. ${ }^{8}$ Service de Médecine Néonatale de Port-Royal, Groupe Hospitalier Cochin, AP-HP, Paris 75014, France. ${ }^{9}$ Faculté de Médecine, Université Paris Descartes, Paris 75006, France.

Received: 8 March 2012 Accepted: 23 October 2012

Published: 31 October 2012

\section{References}

1. [Consensus conference on the management of infant bronchiolitis. Paris, France, 21 September 2000. Proceedings]. Arch Pediatr 2001, 8(Suppl 1):1s-196s.

2. Bar-on ME, Zanga JR: Bronchiolitis. Primary Care 1996, 23:805-819.

3. Wainwright C: Acute viral bronchiolitis in children- a very common condition with few therapeutic options. Paediatr Respir Rev 2010, 11:39-45,

4. Diaz-Caneja A, Gledhill J, Weaver T, Nadel S, Garralda E: A child's admission to hospital: a qualitative study examining the experiences of parents. Intensive Care Med 2005, 31:1248-1254.

5. Graves JK, Ware ME: Parents' and health professionals' perceptions concerning parental stress during a child's hospitalization. Child Health Care 1990, 19:37-42.

6. Board R, Ryan-Wenger N: State of the science on parental stress and family functioning in pediatric intensive care units. Am J Crit Care 2000, 9:106-122.

7. Board R, Ryan-Wenger N: Long-term effects of pediatric intensive care unit hospitalization on families with young children. Heart Lung 2002, 31:53-66. 
8. Board R, Ryan-Wenger N: Stressors and stress symptoms of mothers with children in the PICU. J Pediatr Nurs 2003, 18:195-202.

9. Johnson PA, Nelson GL, Brunnquell DJ: Parent and nurse perceptions of parent stressors in the pediatric intensive care unit. Child Health Care 1988, 17:98-105.

10. Ward-Begnoche W: Posttraumatic stress symptoms in the pediatric intensive care unit. J Spec Pediatr Nurs 2007, 12:84-92.

11. Berger TM, Aebi C, Duppenthaler A, Stocker M: Prospective populationbased study of RSV-related intermediate care and intensive care unit admissions in Switzerland over a 4-year period (2001-2005). Infection 2009, 37:109-116.

12. Cilla G, Sarasua A, Montes M, Arostegui N, Vicente D, Perez-Yarza E, PerezTrallero E: Risk factors for hospitalization due to respiratory syncytial virus infection among infants in the Basque country, Spain. Epidemiol Infect 2006, 134:506-513.

13. Resch B, Pasnocht A, Gusenleitner W, Muller W: Rehospitalisations for respiratory disease and respiratory syncytial virus infection in preterm infants of 29-36 weeks gestational age. J Infect 2005, 50:397-403.

14. Lapillonne A, Gournay V, Gouyon J, Moriette G, Benmedjahed K, Roborel De Climens A, Arnould B, Bendjenana H: The Impact of Bronchiolitis Hospitalization Questionnaire: IBHQ@ - Development of a specific questionnaire assessing the impact on parents of an infant's bronchiolitis-related hospitalization. Orlando, USA: ISPOR 14th annual international meeting; 2009.

15. Impact of Bronchiolitis Hospitalisation Questionnaire (IBHQ ๑). http:// www.proqolid.org/instruments/ impact_of_bronchiolitis_hospitalisation_questionnaire_ibhq_c.

16. Meyer EC, Snelling LK, Myren-Manbeck LK: Pediatric intensive care: the parents' experience. AACN Clin Issues 1998, 9:64-74.

17. Shudy M, de Almeida ML, Ly S, Landon C, Groft S, Jenkins TL, Nicholson CE: Impact of pediatric critical illness and injury on families: a systematic literature review. Pediatrics 2006, 118(Suppl 3):S203-S218.

18. Kline Leidy K, Margolis MK, Marcin JP, Flynn JA, Frankel LR, Johnson S, Langkamp D, Simoes EA: The impact of severe respiratory syncytial virus on the child, caregiver, and family during hospitalization and recovery. Pediatrics 2005, 115:1536-1546.

19. Pezzotti P, Mantovani J, Benincori N, Mucchino E, Di LD: Incidence and risk factors of hospitalization for bronchiolitis in preterm children: a retrospective longitudinal study in Italy. BMC Pediatr 2009, 9:56-56.

doi:10.1186/1471-2431-12-171

Cite this article as: Lapillonne et al:. Impact on parents of bronchiolitis hospitalization of full-term, preterm and congenital heart disease infants. BMC Pediatrics 2012 12:171

\section{Submit your next manuscript to BioMed Central and take full advantage of:}

- Convenient online submission

- Thorough peer review

- No space constraints or color figure charges

- Immediate publication on acceptance

- Inclusion in PubMed, CAS, Scopus and Google Scholar

- Research which is freely available for redistribution 